\title{
Technology: A New Situation For Contemporary Performance
}

\author{
Yi Chen \\ Shanghai Theatre Academy, Shanghai 200040, China \\ bearyi1992@163.com
}

Keywords: technology, contemporary performance, director, designer, audience.

\begin{abstract}
Nowadays, technologies have been widely applied to and greatly influenced on contemporary performance. This essay discusses the opportunities and challenges for directors and designers. It is obvious that technologies enrich the representation of the performance. Then digital performance asks performance makers not only to master the knowledge of performance, but also to do research into digital devices and materials. As a result, it is significant for performance makers to seek for new approaches to balance these two factors in practice. At the same time, technologies raise the audience's interest in contemporary performance and narrow the distance between audience and performance. The paper also argues the audience's attitude towards the situation.
\end{abstract}

\section{Introduction}

Nowadays, the theatre is changing due to the development of the technology. However, many people who are interested in theatre are against the phenomenon. They think the technology will result in the industrialization of theatre. Ursini stated that if theatre didn't catch up the development of the technology, theatre would become a museum [1]. There are many differences between the theatre and the museum. In the theatre, the audience enjoys the spontaneous, alive, interactive and immersive experience. However, the museum is the place to exhibit the work. It is tied, still and unchanging. It is worth well to discuss the changes of theatre influenced by the technology in recent years. This paper aims to present the potentials provided by the technology and talk about the implications for directors, performer and audience. There will be three parts in this paper. Firstly, the technology has an effect on the scenography. Virtual reality generated by the computer develops the organization of space and enhances the immersive of the performance. The experimental drama, Sorcerer and the White Snake 2.0 directed by Spanish Director Pep Gatell from La Fura dels Baus will be taken as an example. On the other hand, the organization of space transforms the artists' approaches of making performance. According to the use of the new materials, there are two approaches. One is material-driven, and the other is content-driven. However, both of them have the limit. Secondly, this paper focuses on the interactivity between the technology and the body. The digital device asks the performance makers to pay more attention to how the physical body interacts with the technology in real time. Digital devices collect and analyze the movement data. The work, Flow No.1 is a case study. As a result, the requirement of the physical body is rising. The performer not only focuses on the physical body, but also understands the technology. After it, the third part introduces the online performance, which narrows the distance between the audience and the character and break up the spatial barriers between the audience and theatre. Because of the Internet, the audience could enjoy the virtual space that allows the performance to take place on the screen of the computer and smartphone at any time. Karen is a good sample well worth to discuss. What's more, the social media also has a positive effect on the communication between the audience and performance maker.

\section{The influence on the scenography}

Space is a basic factor of the performance. Pitches and Popat indicated, "the scenography not only affects the performer directly, but also fundamentally the way a performance is understood" [2]. Nowadays, the technology develops the organization of the stage space. Virtual reality places a significant role in the contemporary scenography. Pimentel and Teixeira stated, "Virtual reality is all about illusion. It is about computer graphics in the theatre of the mind. It's about the use of 
technology to convince yourself you're in another reality” [3]. It is an industrial computer graphics format simulating navigable three-dimensional environment and makes the audience feel like being surrounded by the environment [4]. There are various technical devices applied in the virtual reality, such as projection, different shapes of screens, and expert computer monitor. For theatre, the developments of the virtual reality devices not only improve the virtual reality experience but also distract from real life context [5]. The virtual reality enhances the degree of immersion of the performance. Because of the technology, the directors have more material to make the scenography. What's more, they can transform their imagination into digital figures, which generates the atmosphere helping actors and audiences be devoted into the performance.

The Sorcerer and the White Snake 2.0, 'Baishe Zhuan 2.0' is an experimental drama, which was adapted from Kunqu Opera and directed by Spanish Director Pep Gatell from La Fura dels Baus. The heroin in this play is a spiritual snake that practiced itself into a human woman. In certain scene, the heroin had to switch between a woman and a snake in the hero's presence. The director had to not only illustrate the story but also raise a horrid atmosphere. However, it was impossible to present a physical snake on stage and was difficult for the hero and audience to image the transformation. Then the director organized the virtual reality set which were eight white snake shape curtains in the size of $0.5 \mathrm{~m} * 3 \mathrm{~m}$. These curtains were the background of the projector. The director recorded the video about the heroin in snake costume imitating the movement of a snake temptingly and the physical snake moving in the cave horrifiedly in advance to make a virtual transformation between the heroin and snake. During the performance, the videos about the heroin and snake were projected on the eight curtains, which made the hero and audiences be surrounded by the heroin and snake (figure 1). As in this performance, the audience didn't have fixed seats. They were allowed to move around the space to watch the performance from different angels. When the hero was scared of the videos, shouting and running around the stage, the audience also experienced this emotion as the first-person perspective, which maximized the horrid atmosphere and made an immersive space.

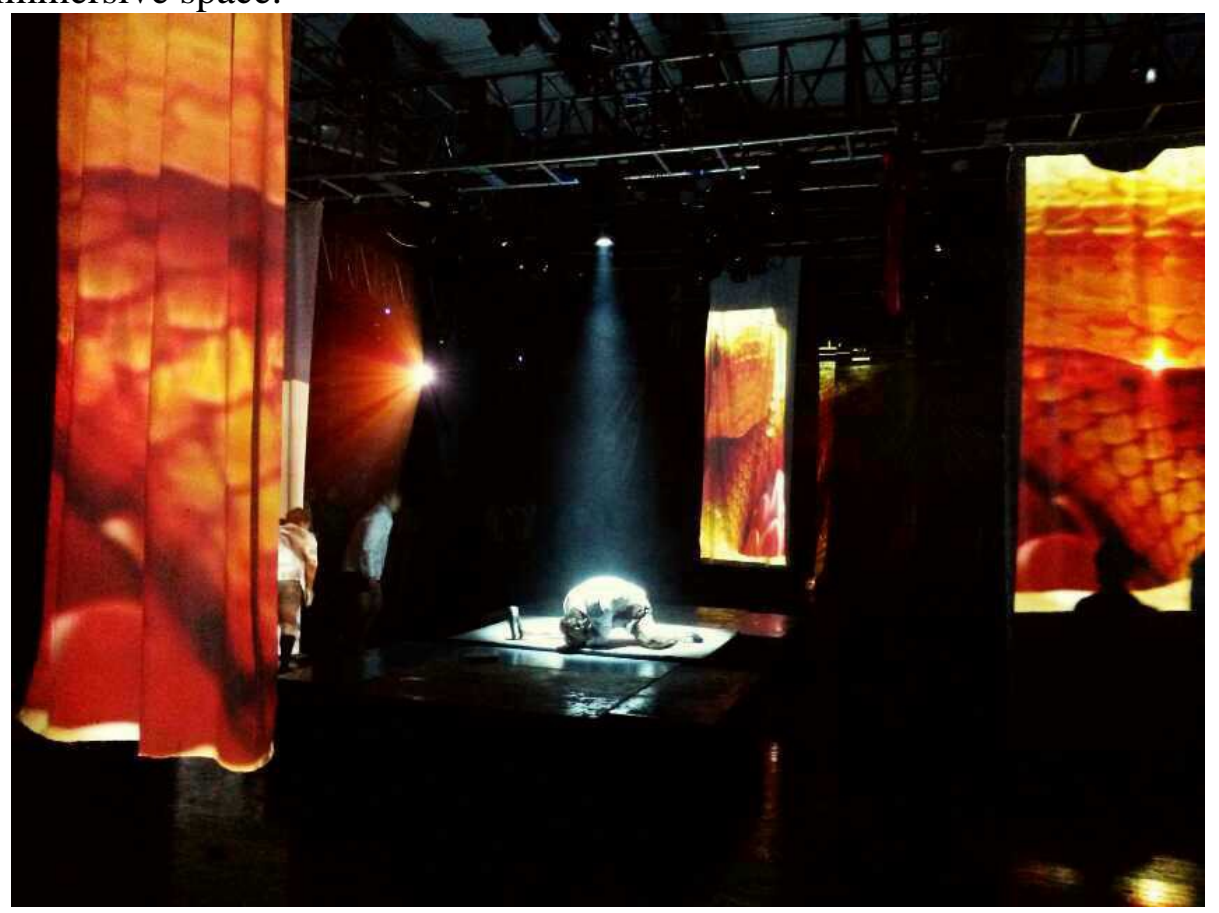

Fig.1 The hero was surrounded by the eight curtains in The Sorcerer and the White Snake 2.0 (Photo: Yi Chen)

The organization of the scenography stands for the director's arrangement of different materials. With the wide applications of the technology in the performance, the directors' approaches to making performance are changing and the directors are facing a lot of challenges. From the early 1700s, the materials-driven had been the main mode. As the technology inspired the directors and 
introduced them the importance of the interactivity and participation, the directors were drawn to test the attributions of new materials in a work. They used new materials to create performative context, attract the audience's attention or emphasiz a kind of notion [6]. However, the technology couldn't maintain the audience's interest for a whole performance. Compared with the technology, the audience paid more attentions to the content. Until 2005, Isabel Valverde raised a new approach, content-driven. Broadhurst and Machon [6] argued that the importance of theme ranked the first, and that the digital materials just acted as tools that help director express narrative ideas. The directors were responsible for emphasizing on the content, rather than devoted themselves into the technology. However, materials and content are different aspects of a performance. Both of them are of great importance. A material-driven work will lack the common experience from the story and a content-driven work will fail because of the innovation. A success application of the digital materials is a context, which changes the way the audience viewed everything in the space and links every section by the technology [6]. The directors are under heavy pressure. For directors in contemporary theatre, it is necessary to not only deepen the understanding of the content, but also catch up the development of the technology. The technology should be applied based on the content. What's more, there will be a bridge between the technology and the content during the creation and make it possible for the audience to enjoy both the technology and the content at the same time. For example, during the process the directors understand the content, they can abstract the emotion expressed in each section firstly and then use the emotion as the bridge, which guides the directors to use the materials to make the context.

\section{The interactivity between the body and the technology}

Interactivity between the audience and the work happens in all art [4]. In the 2000s, everyday life has changed a lot due to the development of technologies, such as mobiles, computers and the Internet. At the same, the rising complexity of technologies influences artistic applications in the performance. Over the past couple of decades, the liveness between the performance and technology has drawn much attention from performance makers [2]. There are two methods of applications widely used, which is based on physical sensors and remote sensors separately [6]. The new equipment and software provides performance makers a number of opportunities of interactivity, especially about how the physical body interacts with the technology in real time. Pitches and Popat emphasized that the body is "the primary mode of access to a lived environment that incorporates digital and physical elements" [2]. For example, the motion tracking asks performance makers to pay more attention on the physical body. Motion tracking is a process of collecting and analyzing the movement data. During this process, the cameras and computers are the essential tools. Cameras are used to catch the actors and attached to computers. Then the computers analyze the information and generate effects as sounds, video and projections. The Vicon is a famous system about motion tracking. In this system, the performer wears a coat attached to computers. On the coat, there are several reflective balls on the certain points of body. A figure consisted of these points can be shown on the computer and the action will be recorded. As a result, the designer can create a new character by giving the figure a "skin" through modeling software and project it on the screen. However, this system is limited, not suitable for the live performance. Because the figure was made in advance, it cannot interact with the live performer.

In 2011, Kinect, a motion-tracking device was released which allows performers to interact with computers in real time. It consisted of the RGB camera, depth sense and multi-array microphone. With them, the gestures can be caught and influence the digital effects on the computer without any hand controller. Flow No.1 is a Kinect projector dance by Princemio, which is a new media dance group in Berlin. As a dancer and an engineer, the director focus on the performance, which is about collaboration between dance and interactive media. Princemio said new media dance helped the director to reach a better understanding of the dance, the technology and communication with the context [7]. In this performance, he was interested in the flow of a dancer and how to express this flow through digital illustrations, and then used the flow as the common characteristic to combine the body 
and the technology as a unity [7]. When the dancer was performing the hip-hop dance, the movement was caught by Kinect and analyzed by the attached computer [7]. At last, the light from projection changing with the movements and shown on the screen behind the performer made up the interactive environment. During the process, the software, such as the msaFluid algorithm and VVVV calibration also made great contributions to the performance. In this performance, the dancer played the leading role and the interactive digital effects acted as the part of the body, not abandoning the body. It is the technologies that ask the performance maker to focus on the physical body and interact with it.

As the improvement of the interactivity between the physical body and the technology, the requirement of the physical body is rising. Because the digital effects are live and decided by the performer movements in real time, the appearance of the interactivity is unique every time [6]. At the same time, the performers also need to give consideration to the interactivity with the other performers and the audience. As a result, the performers are vital and influence the process directly. However, it is the uncontrolled elements in the process that make the interactivity fantastic. Firstly, it is necessary for the performers to exercise the body professionally and do research on the technology. Instead of abandoning the body, the technical equipment belongs to the body [6]. Only achieve a better understanding of the characteristics of the technology, will the performer build the bridge to the technical devices and reply the digital effects appropriately. After receiving the response from the devices, the body recreates the movements and devotes itself to the environment. What's more, compared with interacting with the people, it is more difficult for performer to interact with the technology. Because of the technology, the binaries of the body about death, gender and age are not as clear as usual [2]. The virtual body that the performers interact with has no form and emotion, this asks the performer to imagine the embodiment and give life to the technology. In addition, the audiences are easily tiring of digital effects [6]. For the audiences, it is the body that moves them, not the technology. Because the body is the media that the performer expresses his emotion and identity [8]. Every movement stands for the performer's experience from real life. To make the interactivity meaningful, it is important for performer to perform consciously. Only in this way, the performance will be attractive.

\section{The audience in online performance and social media}

There are similarities between computer games and drama. Firstly, both of them are based on a narrative connecting several characters together. Secondly, these characters have different personalities and improve the development of the story. Thirdly, in the story, the main characters have to overcome some problems which will boots their relationship. What the differences between the games and drama are the audience taking part in the games in the first person and the site where the narrative happens. Dix and Smith stated that the relationship between the audience and the character was closer in the game than in the theatre [4]. In the games, the audience is able to decide the appearance, personality and task of the avatar that stands for self. Participating in the computer game in the first person, the player's loyalty of the game will be strengthened because of creating the avatar, spending time and paying attention to solve the problems in the game [2]. What's more, compared with the sites of the drama, the players can play the computer game at any time with a computer.

It is obvious that the game has huge influence on the performance. With the development of the website, the site of performance has been extended. The differences between the game and performance are gradually disappearing. The performance happens not only in the theatre but also on the Internet. The Internet provides the audience the virtual space that allows the performance to take place on the screen of the computer and smartphone at any time. This virtual space can be called the cyberspace. Pitches and Popat indicated that cyberspace is a world generated by computer "where the corporeal body is transcended, allowing the mind to escape into a place of pure consciousness" [2]. What' more, in the online performance, the importance of the spectator is raised as the spectator becomes the participant. Dixon and Smith stated, although the relationship between the audience and the performers was not as close as before, the spatial barrier between the audience and theatre was 
broken up and the audience acted as prominent as the performers because of the change of the performance site [4].

Karen is a life coach in an app that is created by Blast Theory and combines the gaming and storytelling [11]. When the user starts the app, Karen will ask some questions, which are drawn from psychological profiling questionnaires and about the opinions on the world. From these questions, Karen receives a simple understanding of the user and analyzes the user. Then Karen acts as a friend of the user and is very friendly. She is curious about everything new in her life. When the user opens the app, Karen can't wait to chat with the user directly and asks the user to share the experience with her. When the use has problems and needs suggestions, it is efficient to ask Karen for help. Karen will give the advice based on the analysis of the information supplied by the user. As the friendship between the user and Karen becomes close, Karen gets more and more nosy about the user. If the user doesn't call her usually, Karen will feel sad and needs the user to comfort her as a life coach. Rose said Karen was a personalized experience rather than a movie, because the story was about the user [9]. In the virtual space, the user interacted directly with Karen, the only character and decided the development of the story. Karen is created by Blast theory, a group of artists who focus on the use of interactive media to create performance and interactive art. The artists were attracted by big data and curious about how to analyze the user through big data. The aim of Karen is to help the user get a better understanding of self through data. This work narrows the distance between the audience and the technology. The user takes part in this work by a smartphone feeling like playing a game.

What's more, social media, such as Facebook and Twitter, is of great importance for the audience. Gardner stated that, the social media influenced the audience's decisions about whether to go to the theatre and which performance to enjoy [10]. At first, the social media provides free advertising for the show. Compared with the traditional method, the social media is more effective and efficient. What's more, for the audience, the social media is not only the place to buy tickets in advance or download the pictures, but also the place to communicate with performance makers after the show. The social media allows the performance makers to share anything about the show online, which will help the audience get a better understanding of the show and attract the audience to make comments. This also improves the relationship between the audience and the performance maker.

\section{Summary}

To conclude, the technology makes great contribution to the development of the contemporary performance. For the directors, it provides more possibilities of the organization of space and boots the transformation of the directors' approaches of performance making. Facing this condition, the director needs to not only deepen the understanding of the content, but also catch up the development of the technology. For the performers, the interactivity between the body and technology asks them to train the body professionally and do research on the technology at the same time. In a good interactive performance, the technology acts as the part of the physical body. Only understand the characteristics of the technology, will the performer be able to connect the movement with the technology. For the audience, the online performance offers the experience that is similar to the computer games. The audience is encouraged to take part in the performance by smartphone in the first person and make comments on the social media.

However, if the performance makers rely much on the technology, the technology will have negative effects on the theatre. To catch up the development of the technology, performance makers have to speed the creating process and don't have enough time to test new materials. This will influence the quality of the show. What's more, when the screen is overused on stage, some performances will mix the boundaries between drama and movie and be interrupted because of device problems. For example, Troilus and Gressida had to cancel their performance in Edinburgh because of the computer bugs. But as technology keeps developing, there will be more potential in the future. As the spontaneous, alive, interactive and immersive art, theatre will seek more approaches to renew itself through the digital device. 


\section{Acknowledgements}

Professor Zhixin Liu, Shanghai Virtual Performance Art Lab,

Shanghai Science and Technology Commission of Science and Technology Innovation Plan: The Demonstration Project of multipurpose new media in Shanghai Theatre Academy

\section{References}

[1] G. Ursini Ursic, Josef Svoboda scenographer. [S. 1.]: Union of the Theatres of Europe, 1998

[2] J. Pitches and S. Popat, Performance perspectives. New York: Palgrave Macmillan, 2011, pp.114-145.

[3] K. Pimentel and K. Teixeira, Virtual reality. New York: Intel/Windcrest, 1993.

[4] S. Dixon and B. Smith, Digital performance. Cambridge, Mass.: MIT Press, 2007.

[5] D. Ihde, Bodies in technology. Minneapolis: University of Minnesota Press, 2002.

[6] S. Broadhurst and J. Machon, Performance and technology. Houndsmills, Basingstoke, Hampshire: Palgrave Macmillan, 2006, pp.78-85.

[7] Information on http://princemio.net/portfolio/flow-1-kinect-projector-dance/

[8] Y. Choi, S. Jung, J. Choi, B. Koo and W. Lee, "Immersive Real-Acting Virtual Aquarium with Motion Tracking Sensors”, International Journal of Distributed Sensor Networks, 2014, pp.1-7.

[9]Information on

http://www.nytimes.com/2015/04/05/arts/karen-an-app-that-knows-you-all-too-well.html?_r=0

[10]Information on

http://www.theguardian.com/stage/theatreblog/2010/apr/18/theatre-digital-twitter-facebook-socialmedia

[11] Information on http://www.thespace.org/artwork/view/karen-blast-theory-artwork 